\title{
Air quality real-time operational forecasting system for Europe: an application of the MM5-CMAQ-EMIMO modelling system
}

\author{
R. San José ${ }^{1}$ J. L. Pérez ${ }^{1} \&$ R. M. González ${ }^{2}$ \\ ${ }^{I}$ Environmental Software and Modelling Group, \\ Computer Science School, Technical University of Madrid (UPM), \\ Madrid, Spain \\ ${ }^{2}$ Department of Meteorology and Geophysics, Faculty of Physics, \\ Complutense University of Madrid; Ciudad Universitaria, Madrid, Spain
}

\begin{abstract}
Three dimensional air quality modelling systems have experienced a considerable advance during the last decade. Sophisticated numerical methods have also been developed to gather most of the computer capabilities, which have also experienced important advances. Parallel computing is also an option that is considered more and more important nowadays due to the relatively slow process of single computer processors during recent years. In this contribution we have implemented an air quality real-time operational forecasting system that covers all of Europe by using the MM5-CMAQ-EMIMO air quality modelling system. This system is a step forward from the already developed system that covered the Iberian Peninsula in 2002. The CMAQ 4.5 version (September, 2005) has been incorporated into the application. MM5 and CMAQ models are respectively the meteorological mesoscale and the dispersion drivers. The EMIMO model has been progressively updated by using the new Corine Land Cover for Europe (EEA) with $100 \mathrm{~m}$ spatial resolution. We have developed a GIS oriented Internet interface that allows the user immediate access to pollution time series and hourly maps for the next 48-72 hours forecast for criteria pollutants (those limited by the corresponding EU Directives). The visual information is adapted to the specific legislation for each pollutant so that the information is related to the possible exceedances of the different concentrations averaged over different periods of time.
\end{abstract}




\section{Introduction}

Air pollution modelling tools have become an important tool for local, regional, national and continental environmental authorities. The air quality modelling systems can be used in historical mode and forecasting mode. The historical mode is defined when the simulation tool is applied to reproduce in time and space the different concentrations of different pollutants which have been observed in past times. Most of the areas are not covered by monitoring stations and the results produced by the model in historical mode can be used for research purposed and also to know the level of concentrations on those areas when no monitoring stations are found. On the contrary, the air pollution dispersion models can be used in forecasting mode. In this case the simulated period covers initially a period in the "past" and immediately the simulation goes to the "future" times. Obviously, the CPU time should significantly lower than the simulated period in order to have an effective approach. Air Quality modelling systems which are used in forecasting mode requires a number of conditions and requirements which are different from those simulations in historical mode.

The need to have air quality forecasts in detail in space and time is becoming more important since the environmental authorities and citizens are requiring air quality information in advance in order to take measures and actions to eventually be protected from pollution episodes but also to have a proper knowledge of the air quality in the areas where they live or they are going to visit.

In this contribution we have used the MM5 meteorological mesoscale model developed by Pennsylvania State University (USA) and NCAR (National Centre for Atmospheric Research, USA) [2]. The CMAQ model is the Community Multiscale Air Quality Modelling System developed by EPA (USA) [1] and EMIMO is the Emission Model developed by San José R. et al. (2003) [4]. MM5 is a well recognized non-hydrostatic mesoscale meteorological models which uses global meteorological data produced by global models such as GFS model (NCEP, USA) to produce high resolution detailed three dimensional fields of wind, temperature and humidity which are used in our case as input for the photochemical dispersion model CMAQ [3]. In addition of MM5 output data, EMIMO model produces for the specific required spatial resolution, hourly emission data for different inorganic pollutants such as particulate matter, sulphur dioxide, nitrogen oxides, carbon monoxide and total volatile organic compounds VOC's. The VOC's are splitted according to SMOKE (Sparse Matrix Operator Kernel Emissions [5] and [6]. In this particular case, the EMIMO model is applied by using the annual EMEP official emissions from 2003 for the whole of Europe. The full system is called OPANA V3 since the V2 included adaptations of the MEMO model (REMEST) [7] and on-line implementation of the SMVGEAR (Sparse Matrix Vector Gear Technique) implicit technique with the CBM-IV chemical carbon bond mechanism. 


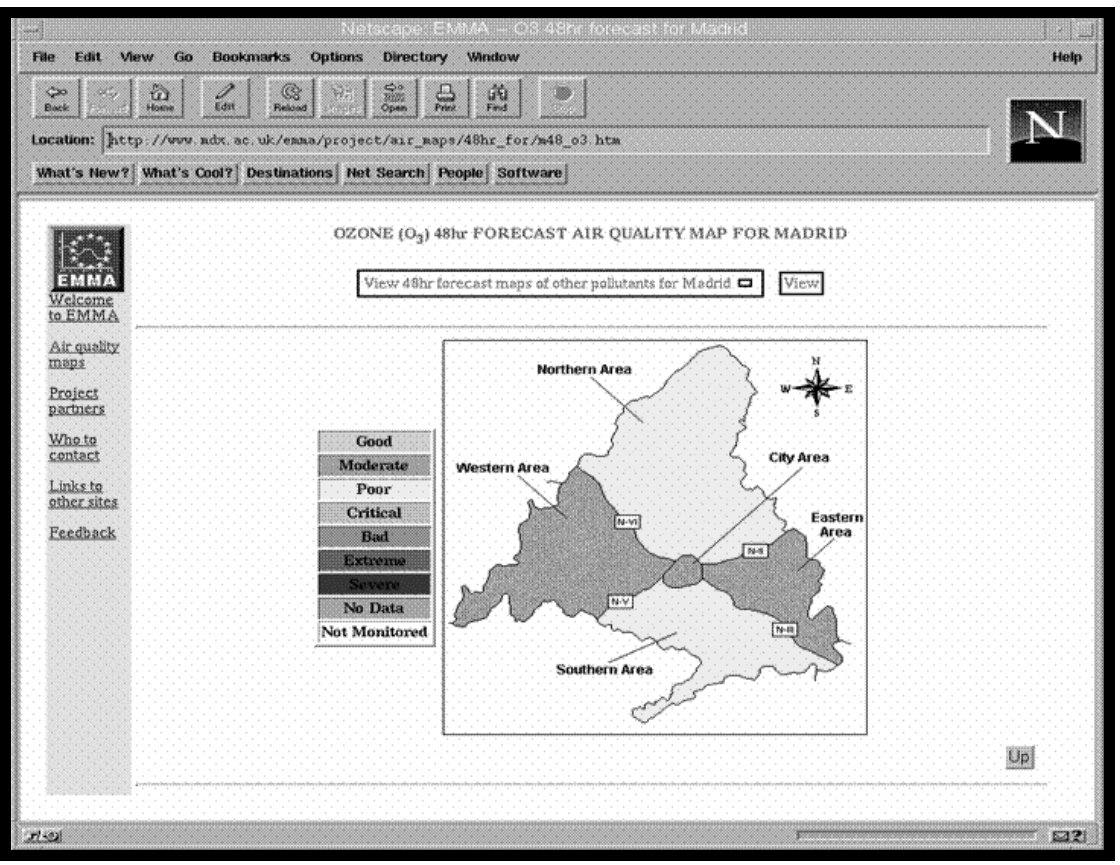

Figure 1: EMMA results with air quality index over Madrid Community for $\mathrm{O}_{3}$ pollutant during the EU IST EMMA project.

During the last decade, we have developed several air quality modelling systems to provide air quality forecasts for different areas, regions and cities. In 1996 we developed a system into the EMMA EU project. This project brought together several EU countries to build different air quality forecasting systems focused on city European areas. An adaptation of the ANA model (Atmospheric Numerical pollution model for urban and regional Areas) was developed for this stage called OPANA V1. The operational version of the system is called OPANA V1. This system provided air quality forecasts in real-time for Madrid City and Madrid Community Areas. This was of the first tries to use sophisticated three dimensional Eulerian models - based on non-hydrostatic mesoscale meteorological models - to produce daily services related to 48-72 hours forecasts for criteria pollutants. Figure 1 shows some results of the application of OPANA V1 over Madrid Community during the EMMA EU IST project. OPANA V1 used the EMIMA model (EMIssions Madrid). An emission model developed to take into account the detailed $1 \mathrm{~km}$ emissions for Madrid Municipality in 1995. In 1999, a first version of the EMIMO model [4] was developed and applied in OPANA which generated the OPANA V2 air quality forecasting system. This model was applied over several other cities and regions and particularly into the EQUAL project (Electronic Services for a Better Quality of Life), the model was applied to provide daily forecasts for Bilbao (Spain) and Leicester City Council (United Kingdom). In Bilbao the system was 
lunched daily by operators in the Bilbao Municipality and in Leicester, the system was also operated by Internet by our laboratory. This service for Leicester City Council continues in operation nowadays. Figure 2 shows an example of the OPANA V2 operating to provide air quality forecasts for Leicester City Council area for criteria pollutants.

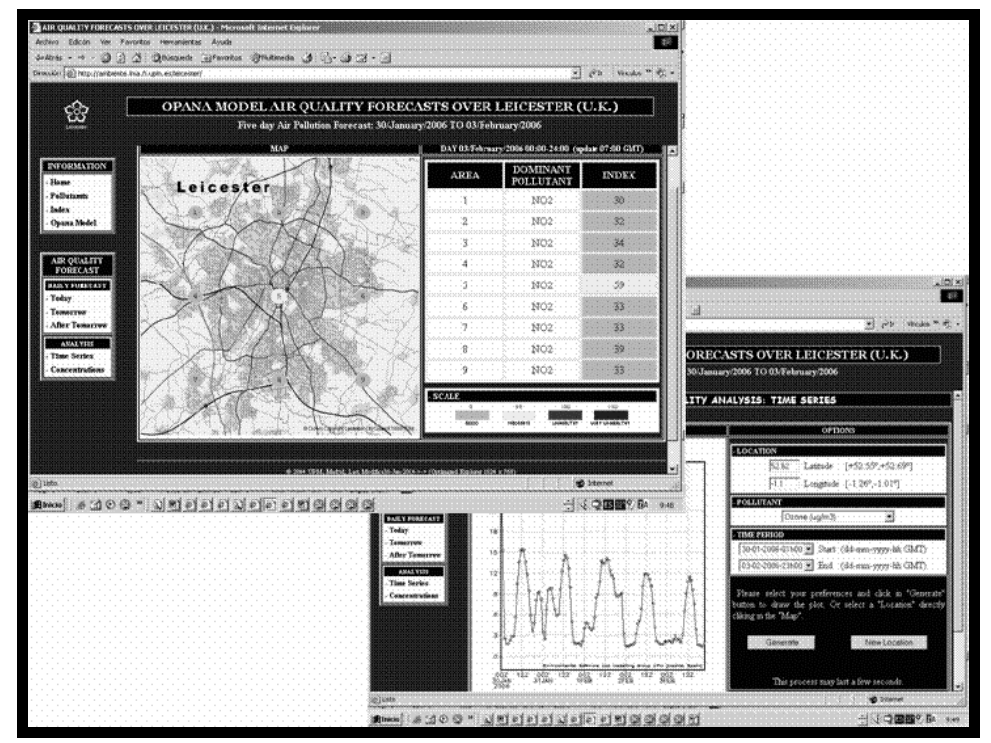

Figure 2: Leicester City Council (U.K.) air quality forecasts by using OPANA V2 air quality forecasting system during the EQUAL EU IST project.

In addition to these projects, in 2001, we developed a version for Madrid Municipality which has been in operation since that year by using OPANA V2. This system is operating since last year with a web internal version for Madrid Municipality. In Figure 3 we observe a daily report for Air Quality Index in Madrid by using OPANA V2. During the APNEE and APNEE-TU IST EU projects the OPANA V2 was applied to provide air quality forecasts services during the duration of the project. During these projects a sophisticated GIS/WEB system was implemented to provide the pollution information. In addition, all services in these cases were provided by using Internet technology. Additionally, an SMS and WAP warning service was establish during these projects. These mobile telecommunication technologies was providing air pollution warning services according to the results produced by OPANA V2 for Andalusia (Spain) and Canary Islands (Spain) region. In Figures 4 and 5 we observe two samples of these services during the duration of the EU IST Projects.

In July 2002, a new version of OPANA was produced and included MM5 and CMAQ mesoscale meteorological and air dispersion modelling systems to 
produce the air quality forecasts. EMIMO continue to be the emission model provider. This system was called OPANA V3. This model was applied in Las Palmas de Gran Canaria Municipality in Gran Canaria Island in Canary Islands for Las Palmas de Gran Canaria Municipality. The service by Internet started in February 2003 and continues up to now. In Figure 5 we show a sample of the daily air quality forecasts for the city with $1 \mathrm{~km}$ spatial resolution and 1 hour pollution concentration forecasts. This model included PM10 forecasts.

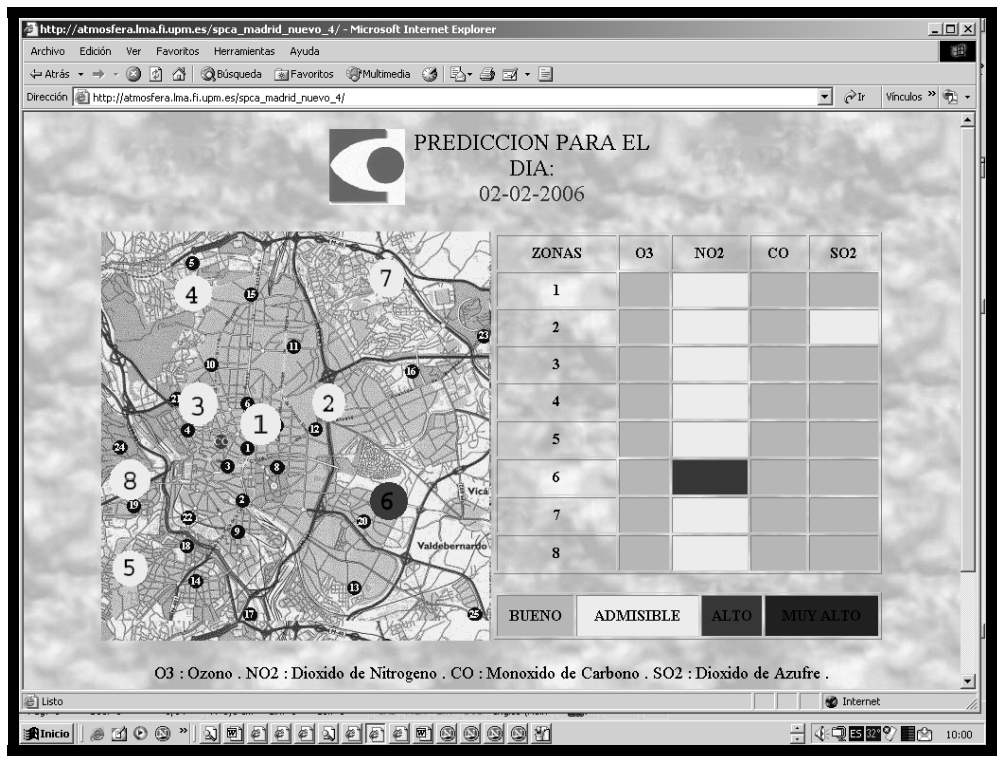

Figure 3: Air Quality forecast as published in the Madrid Municipality Web site for February 2, 2006. This service is provided by OPANA V2 for Madrid Municipality since 2001.

\section{Operational OPANA V3 system over Europe}

Since September 2000 we are providing meteorological forecasts for Iberian Peninsula by using MM5 mesoscale meteorological model with $27 \mathrm{~km}$ spatial resolution. The system can be accessed in http://atmosfera.lma.fi.upm.es/ mm5v3.6/ from our central home page in http://artico.lma.fi.upm.es. In October 2002 we were producing for a limited period of time air quality forecasts by using MM5-CMAQ (included into OPANA V3) as seen in our central home site and linked to http://atmosfera.Ima.fi.upm.es/cmaq/. Since December 2005 we are producing experimental air quality forecasts by using MM5-CMAQ-EMIMO for the whole of Europe with $50 \mathrm{~km}$ spatial resolution. The results are shown in the Internet for the next 96 hours including the actual day. The system shows a zoom-in capability including roads and railroads which helps the user to identify the location where he/she is interested in. The system also provides detailed pollutant time series for the spatial location selected by the Internet user. In figures 6 and 7 we two examples of the capabilities of the system. 


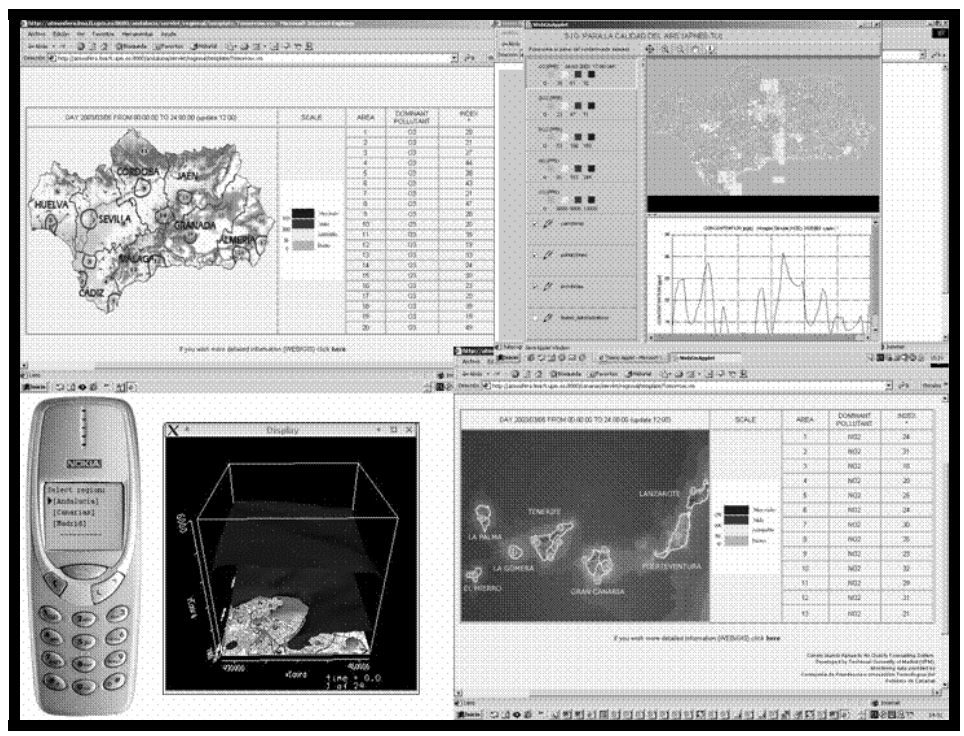

Figure 4: APNEE mobile telecommunication and Internet technologies applied by using the air quality forecasts produced by OPANA V2 modelling system over Canary Islands and Andalusia (Spain) Communities.

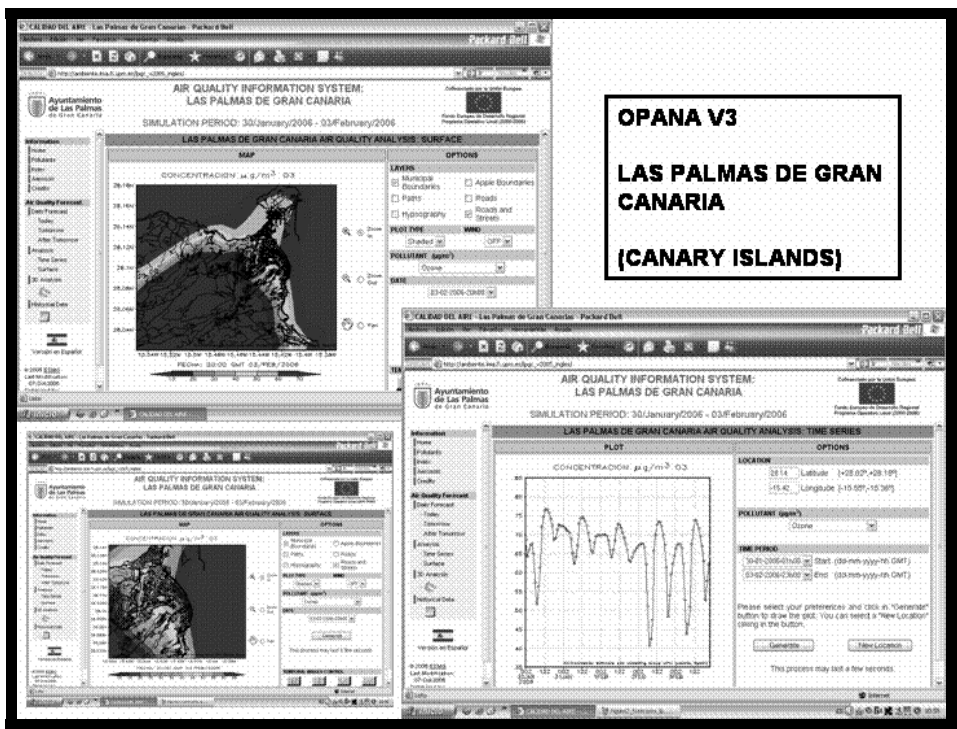

Figure 5: Views of the OPANA V3b operational services for Las Palmas de Gran Canaria (Canary Islands, Spain) producing air quality forecasts with $1 \mathrm{~km}$ spatial resolution and 3D visualization system over the Internet. 


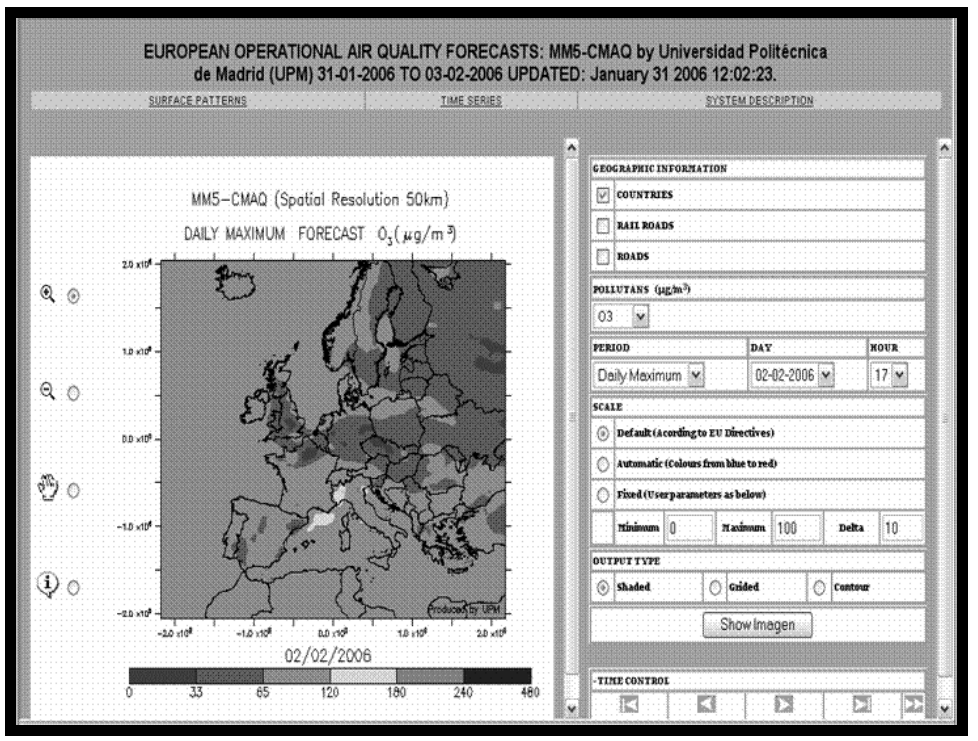

Figure 6: European Operational Air Quality Forecasts by using MM5CMAQ-EMIMO (OPANA V3) for February 2, 2006 for Ozone maxima.

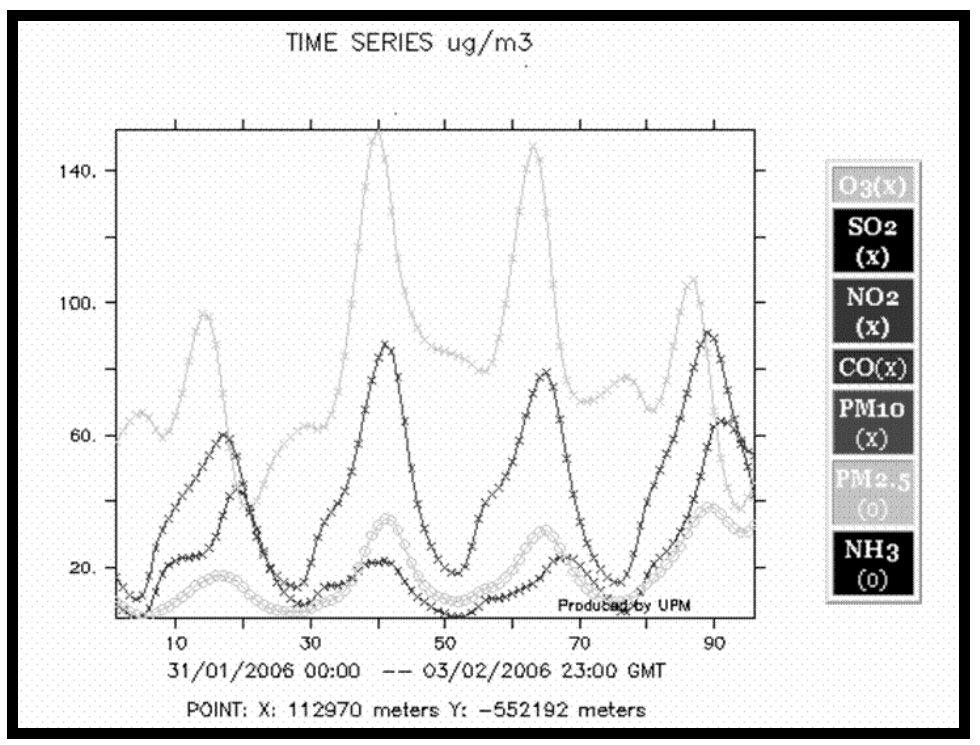

Figure 7: Pollutant time series for $\mathrm{O}_{3}, \mathrm{NO}_{2}, \mathrm{PM} 10$ and PM2.5 as produced by the OPANA V3 air quality forecasting system for Europe during the period of January 31. 2006 - February 3, 2006 in a location in the North-West of Italy. 
The system is actually in experimental mode which means that several changes can be implemented in real-time and it is currently a research tool. The European operational air quality forecasting system by using MM5-CMAQEMIMO modelling system provides also the daily maximum and the daily average. Also different pollutant time series can be produced according to the geographical location selected by the Internet user by clicking over the European map. Hourly maps and time series are produced as requested by the Internet user.

The system is using the CBM-IV chemical scheme to produce the air quality forecasts and the Lambert Conformal Conical Projection to run CMAQ and show the results in the Internet.

The system has been evaluated by comparing the modelling results and the observed results in different air quality monitoring stations in Madrid area. In Figure 8 we show the comparison between observed and modelled data for Majadahonda monitoring station (a monitoring station located in the north-west area of Madrid City and at about $20 \mathrm{~km}$ distance) for the August 1-5, 2003 hot wave period in Europe. Dotted lines are modelling data and continuous line is observed data from monitoring station. Observe how the model is producing

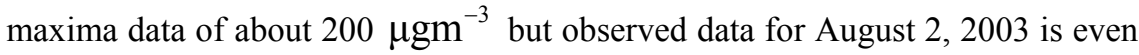
higher $\left(220 \mathrm{ggm}^{-3}\right)$ but the general agreement is quite good.

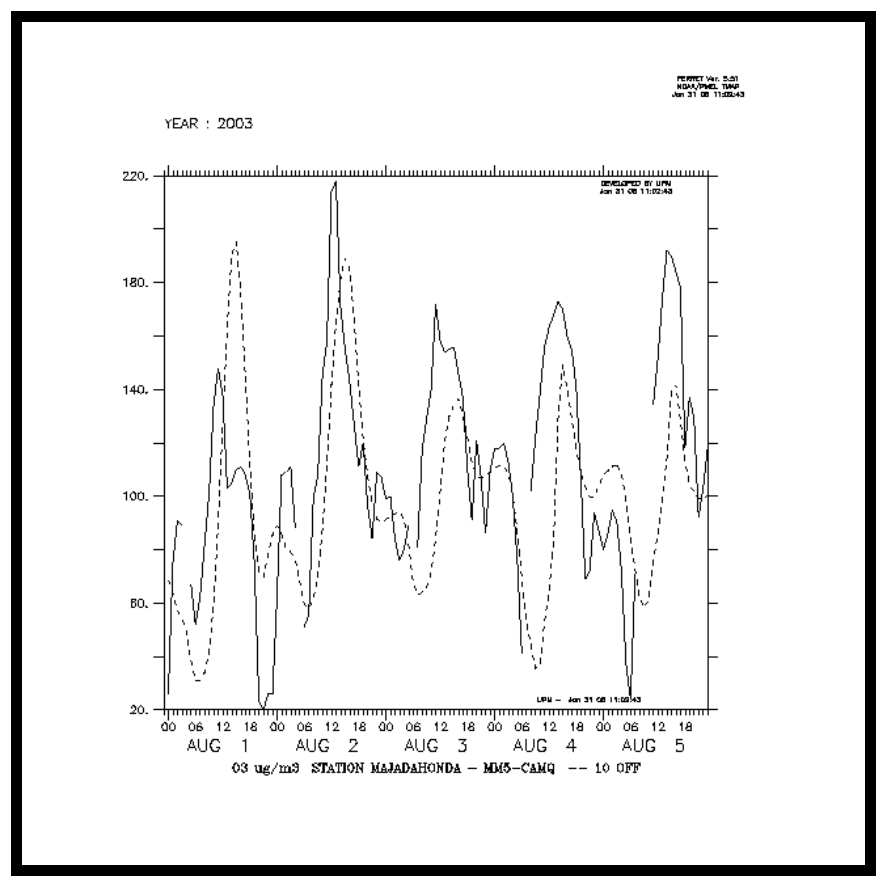

Figure 8: Comparison between MM5-CMAQ-EMIMO modelled $\mathrm{O}_{3}$ concentrations and observations at Majadahonda (Madrid, Spain) monitoring station during the "hot wave" period of August 2003 in Europe. 


\section{Conclusions}

The MM5-CMAQ-EMIMO modelling system (OPANA V3) has been implemented in experimental mode to produce daily European Air Quality Forecasts for Europe with $50 \mathrm{~km}$ spatial resolution and 23 vertical layers (up to $100 \mathrm{mb}$ ). The system is operational since December 2005 and it is producing daily air quality forecast maps and time series for Europe. Time series are produced according to Internet user request geographical location by clicking on the map over the Internet map and selecting the information box. The system is planned to incorporate additional features in the near future such as access to historical data, analysis of exceedances at different European regions, etc. The system is also planned to be used to provide initial and boundary conditions for future nesting air quality forecasting areas in Europe at national, regional and city level.

\section{Acknowledgements}

We would like to thank EPA/PSU/NCAR for providing the MM5-CMAQ modeling system. This project is fully funded with our UPM resources.

\section{References}

[1] Byun, D.W., J. Young, G. Gipson, J. Godowitch, F. Binkowsky, S. Roselle, B. Benjey, J. Pleim, J.K.S. Ching, J. Novak, C. Coats, T. Odman, A. Hanna, K. Alapaty, R. Mathur, J. McHenry, U. Shankar, S. Fine, A. Xiu, and C. Lang, 1998. Description of the Models-3 Community Multiscale Air Quality (CMAQ) model. Proceedings of the American Meteorological Society $78^{\text {th }}$ Annual Meeting Phoenix, AZ, Jan. 11-16, 1998. pp. 264-268.

[2] Grell, G., J. Dudhia, and D. Stauffer 1994: A Description of the Fifty Generation Penn State/NCAR Mesoscale Model (MM5). NCAR Tech. Note, TN-398+STR, 117 pp.

[3] San José R., Prieto J.F., Castellanos N. and Arranz J.M. (1997) Sensititivity study of dry deposition fluxes in ANA air quality model over Madrid mesoscale area, Measurements and Modelling in Environmental Pollution, Ed. San José and Brebbia, pp. 119-130.

[4] San José R., Peña J.I., Pérez J.L. and González R.M. (2003) EMIMO: an emission model. 292-298. ISBN: 3-540-00840-3 Springer-Verlag.

[5] Williams, A., M. Caughey, H.-C. Huang, X.-Z. Liang, K. Kunkel, Z. Tao, S. Larson, and D. Wuebbles, 2001: Comparison of emissions processing by EM-S95 and SMOKE over the Midwestern U.S. Preprint of International Emission Inventory Conference: One Atmosphere, One Inventory, Many Challenges. Denver, Colorado, May 1-3, pp. 1-13.

[6] Coats, C.J., Jr. 1995. High Performance Algorithms in the Sparse Matrix Operator Kernel Emissions (SMOKE) Modelling System, 
Microelectronics Center of North Carolina, Environmental Systems Division, Research Triangle Park, NC, 6 pp.

[7] Flassak T. and Moussiopoulos N. (1987). An application of an efficient non-hydrostatic mesoscale model", Boundary Layer Meteorology, 41, pp. $135-147$. 